\title{
ESTIMATIVAS DE PARÂMETROS RELACIONADOS AO MELHORAMENTO GENÉTICO DA ERVA-MATE: POSSIBILIDADE DE SELEÇÃO PRECOCE
}

\section{GENETIC BREEDING AND ITS RELATED TRAITS ESTIMATION IN JUVENILE AGE IN ERVA-MATE}

\author{
José Sebastião Cunha FERNANDES ${ }^{1}$ \\ Silvio USHIWATA ${ }^{2}$ \\ Rebeca de Mattos DAMINELLI ${ }^{3}$ \\ Juarez GABARDO ${ }^{4}$ \\ Massato KOBIYAMA ${ }^{5}$ \\ Agenor MACCARI JUNIOR ${ }^{6}$ \\ Celso PREVEDELLO ${ }^{7}$ \\ Rosângela Maria Simeão RESENDE ${ }^{8}$ \\ Marcos Deon Vilela RESENDE ${ }^{9}$ \\ José Alfredo STURION ${ }^{10}$
}

\begin{abstract}
RESUMO
No final de julho de 1997 foi montado, na Estação Experimental do Cangüiri/UFPR, um experimento com erva-mate, latice $8 \times 8$ (64 progênies de meios-irmãos originadas de cinco procedências), com nove repetições balanceadas e seis plantas por parcela, perfazendo um total de 3456 plantas, num espaçamento de 1,6 m entre plantas e 2,5 m entre fileiras. Por se tratar de uma espécie perene, os objetivos deste experimento são enfocados em um longo prazo, durante o qual pretende-se promover o melhoramento genético desta espécie, bem como desenvolver outros estudos de importância para a sua exploração. Os caracteres analisados foram taxa de mortalidade aos quatro e 12 meses da data de plantio e altura de planta aos 12. Os resultados permitiram concluir que a distribuição de mortalidade aos quatro meses não foi influenciada por progênies ou procedências. Aos 12 meses, entretanto, houve evidências de maior suscetibilidade à mortalidade de certas progênies e, principalmente, procedências. Efeitos significativos para o caráter altura de planta foram observados para procedências e progênies dentro destas. Estimativas da herdabilidade no sentido restrito e no nível de indivíduos variaram entre as procedências. As progênies de Barão de Cotegipe, além de apresentarem a menor taxa de mortalidade, mostraram também a maior média e a maior variância genética aditiva para o caráter altura de planta.
\end{abstract}

Palavras-chave: erva-mate, mortalidade, teste de progênies, melhoramento genético.

\footnotetext{
1 Engenheiro Agrônomo, Doutor, Professor Adjunto III, Departamento de Genética/UFPR, CP 19071, CEP 81531-990, Curitiba, PR, Fax (0**41) 266-2042. E-mail: cunha@bio.ufpr.br $\equiv$ Autor para correspondência.

2 Acadêmico de Agronomia/UFPR, Estagiário PIBIC/CNPq.

3 Acadêmica de Biologia/UFPR, Estagiária voluntária.

4 Engenheiro Agrônomo, Professor Adjunto I, Departamento de Genética/UFPR.

${ }^{5}$ Bacharel em Ciências Naturais, Doutor, Professor Adjunto III, Departamento de Solos/UFPR.

${ }^{6}$ Engenheiro Agrônomo, M.Sc., Professor Assistente III, Departamento de Solos/UFPR.

7 Engenheiro Agrônomo, Doutor, Professor Titular, Departamento de Solos/UFPR.

8 Bacharel em Biologia, Doutoranda no Curso de Pós-Graduação em Genética/UFPR.

${ }^{9}$ Engenheiro Agrônomo, Doutor, Pesquisador do Centro Nacional de Pesquisas Florestais/EMBRAPA.

${ }^{10}$ Engenheiro Florestal, Doutor, Pesquisador do Centro Nacional de Pesquisas Florestais/EMBRAPA.
} 


\section{ABSTRACT}

An $8 \times 8$ balanced lattice, with 9 repetitions and 6 plants per plot, performing a total of 3.456 plants (64 half-sib progenies of "erva-mate" - Ilex paraguariensis St. Hil. - distributed among five populations from different sites in the States of Paraná and Rio Grande do Sul), was set up at the UFPR Cangüiri farm. The distances between plants and rows were 1,6 $\mathrm{m}$ and 2,5 $\mathrm{m}$ respectively. The aim of this trial is to genetically improve these populations as well as to develop other studies considered important for the culture. The traits evaluated were mortality rate at the age of 4 and 12 months, and plant height at 12 months, from the date the trial was set up. The results showed that mortality rate at four months was not affected by progenies nor by populations. At twelve months, on the other hand, some progenies and mainly populations showed a higher mortality rate. Significant effects for plant height were detected for populations and progenies within them. Barão de Cotegipe site showed the highest individual narrow sense heritability, the highest average for plant height, and the lowest mortality rate.

Key-words: erva-mate, stand, progeny test, genetic improvement.

\section{INTRODUÇÃO}

A produção anual de erva-mate cancheada nos Estados do Sul do Brasil (PR, SC e RS) é estimada em 210 mil toneladas, com receita em torno de 150 milhões de reais (11). Entretanto, o extrativismo e o baixo nível tecnológico são ainda típicos da cultura nestes Estados (14). Estudos de genética e melhoramento, bem como programas de produção de propágulos melhorados, sendo escassos, são apontados como as principais causas da baixa qualidade genética e fisiológica das sementes usadas para plantio nas últimas décadas (09). Considerando-se que há uma década atrás já se plantavam na Região Sul, anualmente, cerca de 15 milhões de mudas (03), não é surpresa a constatação de que a maioria dos ervais é caracterizada por alta heterogeneidade, alta mortalidade e baixa produtividade. Em ervais com estas características, estima-se que $35 \%$ das plantas sejam responsáveis por mais de $50 \%$ da produção (01).

A preocupação científica em relação à ervamate é mais recente no Brasil (04) se comparada com o desenvolvimento alcançado com outros vegetais e produtos. Atualmente, entretanto, importantes grupos de pesquisadores decidiram investir em várias linhas de pesquisa ligadas à produção e à industrialização da erva-mate, nos três Estados do Sul brasileiro.

Os trabalhos oriundos deste investimento foram divulgados por seminários, reuniões, encontros e congressos. Assim, os pesquisadores do Centro Nacional de Pesquisa de Florestas da Empresa Brasileira de Pesquisa Agropecuária (CNPF/EMBRAPA) organizaram, em 1983, no próprio CNPF, um seminário dedicado especificamente à cultura da erva-mate, cujos anais foram publicados em 1985 pela editora deste centro, sendo importante fonte de informação a respeito desta cultura. Outro evento importante foi a I Reunião Técnica do Cone Sul Sobre a Cultura da Erva-Mate, com a participação da Universidade
Federal do Rio Grande do Sul (UFRGS) e de outras instituições. Este evento aconteceu em Porto Alegre, RS, em setembro de 1992, e os resultados foram também publicados (14). Em novembro de 1997 aconteceu a II Reunião Técnica do Cone Sul Sobre a Cultura da Erva-Mate, organizada pelos pesquisadores do CNPF/EMBRAPA, no município de Colombo, PR.

Outro aspecto, também relevante, é a ervamate no contexto do Mercosul. É possível que nenhum outro produto, com intenso cultivo e grande expressão econômica, seja tão característico de uma região onde se está a organizar uma comunidade econômica (04).

Considerando-se a atual situação e as perspectivas da erva-mate na Região Sul do Brasil, projetos envolvendo estudos básicos e aplicados nesta cultura tornam-se bem-vindos. Assim, o presente trabalho faz parte de um projeto maior, cujo objetivo é promover o melhoramento genético de características de interesse econômico (produção de massa verde, resistência a pragas e doenças, qualidade etc.) nesta espécie, por meio de testes de procedências e progênies.

Os objetivos específicos deste trabalho foram: a) verificar a influência de procedências e progênies na taxa de mortalidade das plantas aos quatro e 12 meses da data de plantio; e b) estimar componentes de média e de variância genética para o caráter altura de planta aos 12 meses da data de plantio.

\section{METODOLOGIA}

O CNPF/EMBRAPA, localizado no município de Colombo, PR, promoveu uma grande coleta de germoplasma em oito municípios diferentes, sendo sete no PR (Ivaí, Colombo, Quedas do Iguaçu, Pinhão, Antônio Olinto, Cascavel e São Mateus do Sul) e um no RS (Barão de Cotegipe). Considerandose a distância entre esses municípios, as progênies coletadas em cada um podem ser consideradas 
como uma população ou procedência (09). Parte dessas progênies, já em estádio de muda, foram cedidas para a UFPR, num total de cinco procedências (Ivaí, Colombo, Quedas do Iguaçu, Cascavel e Barão de Cotegipe) com 15 progênies cada, perfazendo então um total de 75 progênies.

Em função das condições do local disponível para a instalação do ensaio, optou-se por um delineamento em blocos incompletos balanceados. Assim, foram eliminadas duas progênies de cada procedência do PR e três do RS, montando-se então um latice $8 \times 8$, com nove repetições balanceadas com seis plantas por parcela, num total de 3456 plantas, espaçadas 1,6 m entre plantas e 2,5 m entre fileiras.

Um aspecto importante a considerar é o tamanho efetivo $\left(\mathrm{N}_{\mathrm{e}}\right)$ das populações usadas neste experimento (12 matrizes para aquela originada do RS e 13 para as demais originadas do PR). Como cada matriz está representada por $9 \times 6=54$ indivíduos e, considerando-se que a espécie é dióica, 12 e 13 matrizes representam um $\mathrm{N}_{\mathrm{e}}$ de aproximadamente 47 e 51, respectivamente. Embora seja usual considerar cada procedência como uma população (09), a população-base para seleção, para o presente propósito, é constituída pelas cinco procedências que se encontram neste experimento, devido às limitações do $\mathrm{N}_{\mathrm{e}}$ mencionadas. Tal decisão justifica-se considerandose que o número adequado de progênies para representar uma população alógama monóica é no mínimo 20 ( $\mathrm{N} \cong 80)(10)$.

Duas variáveis foram analisadas: taxa de mortalidade aos quatro e 12 meses da data de plantio e altura de planta aos 12 meses da data de plantio.

Para comprovar a hipótese de diferenças nas taxas de mortalidade entre progênies e procedências, foi utilizado o teste de Qui-quadrado para aderência.

Para a variável altura de planta foi usado o modelo matemático a seguir, com todos os efeitos aleatórios, exceto a média:

$$
Y_{i j k}=m+p f_{i}+r_{j}+e_{i j}+d_{i j k}
$$

em que:

$$
\begin{gathered}
\begin{array}{c}
i=1,2, \ldots, \mathrm{I}, \text { sendo } \mathrm{I}=64 ; \\
j=1,2, \ldots, \mathrm{J}, \text { sendo } \mathrm{J}=9 ; \\
k=1,2, \ldots, \mathrm{K}, \text { sendo } \mathrm{K}=6 ; \mathrm{e}
\end{array} \\
(p f)_{i}=\bar{Y}_{i . .}-\bar{Y}_{\ldots} \begin{array}{r}
\text { = efeito da família i, incluindo- } \\
\text { se efeitos de procedências; }
\end{array} \\
r_{j}=\bar{Y}_{. j .}-\bar{Y}_{\ldots}=\text { efeito da repetição j; }
\end{gathered}
$$

$$
\begin{aligned}
& e_{i j}=\bar{Y}_{i j .}-\bar{Y}_{i . .}-\bar{Y}_{. j .}+\bar{Y}_{. . .} \begin{array}{l}
\text { efeito da parcela } \\
\text { ij, ou seja, da } \\
\text { progênie i na } \\
\text { repetição j; }
\end{array} \\
& d_{i j k}=Y_{i j k}-\bar{Y}_{i j .}=\text { efeito do indivíduo k dentro da } \\
& \text { parcela ij; } \\
& \bar{Y}_{. .}=m=\text { média geral; } \\
& \bar{Y}_{i . .}=\text { média da família i no ensaio; } \\
& \bar{Y}_{. j .}=\text { média da repetição j no ensaio; }
\end{aligned}
$$

Observa-se que o modelo usado foi relativo a um delineamento em blocos casualizados e não a um latice.

Várias herdabilidades foram estimadas a partir das observações coletadas, a saber:

$h_{d}^{2}=$ herdabilidade associada ao efeito do indivíduo dentro da parcela;

$h_{p}^{2}=$ herdabilidade associada ao efeito de parcela;

$h_{f}^{2}=$ herdabilidade associada ao efeito de progênie;

$h_{r}^{2}=$ herdabilidade associada ao efeito de repetição.

Os estimadores para cada herdabilidade (8) são:

$$
\begin{aligned}
& h_{d}^{2}=\frac{\left(1-r_{g}\right) \sigma_{A}^{2}}{\sigma_{d}^{2}} \\
& h_{p}^{2}=\frac{\frac{\left(1-r_{g}\right)}{K} \sigma_{A}^{2}}{\sigma_{A}^{2}+\frac{\sigma_{d}^{2}}{K}}
\end{aligned}
$$

$$
\begin{aligned}
& h_{f}^{2}=\frac{\frac{\left(1+(J K-1) r_{g}\right)}{J K} \sigma_{A}^{2}}{\sigma_{f}^{2}+\frac{\sigma_{e}^{2}}{J}+\frac{\sigma_{d}^{2}}{J K}} \\
& h_{r}^{2}=\frac{\frac{\left(1-r_{g}\right)}{I K} \sigma_{A}^{2}}{\sigma_{f}^{2}+\frac{\sigma_{e}^{2}}{J}+\frac{\sigma_{d}^{2}}{I K}}
\end{aligned}
$$


em que $r_{g}$ é duas vezes a probabilidade de dois alelos de um loco, tomados ao acaso em dois indivíduos, serem idênticos por origem. Para progênies de meios-irmãos, que é o presente caso, $r_{g}=1 / 4$.

O numerador de cada uma destas expressões é a co-variância entre a unidade da população em que a seleção está sendo conduzida e a unidade da população melhorada. O denominador é a variância fenotípica da unidade de seleção.

Os parâmetros $\sigma_{A}^{2}$ (variância genética aditiva que é a variância devida aos efeitos médios dos alelos), $\sigma_{d}^{2}$ (variância observada entre indivíduos dentro das progênies que é de natureza genética e ambiental), $\sigma_{f}^{2}$ (variância entre progênies que corresponde a $\frac{1}{4} \sigma_{A}^{2}$ e $\sigma_{e}^{2}$ (variância devido à interação entre repetições e progênies que é o erro experimental) foram todos estimados pelas esperanças matemáticas dos quadrados médios para os efeitos do modelo em questão que, conforme já foi dito, é aleatório.

É pertinente informar que o caráter altura de planta, em qualquer idade, não tem nenhuma importância direta no melhoramento desta cultura. Entretanto, em se tratando de resposta correlacionada entre diferentes caracteres em diferentes idades, tal caráter pode ser de grande importância. Assim, se houver variância genética significativa para altura de planta em idade precoce, o próximo passo é verificar se este caráter co-varia geneticamente com a produção de massa verde em idade de plena produção comercial. Dependendo da magnitude e significância desta correlação genética, muito tempo poderá ser economizado pela seleção em estádio precoce.

\section{RESULTADOS E DISCUSSÃO}

\section{Taxa de mortalidade}

A hipótese de diferenças na taxa de mortalidade para progênies pode ser descartada, pelo menos para a primeira avaliação de mortalidade (quatro meses após o plantio), uma vez que a freqüência de falhas por progênie segue distribuição Poisson (Tabela 1). Portanto, não existe evidências de que haja qualquer progênie, dentre as 64 testadas, com maior índice de mortalidade. Entretanto, a avaliação de mortalidade aos 12 meses após o plantio não mostra uma distribuição tão conclusiva (Tabela 2). Apesar de o teste $\chi^{2}$ não ser significativo, seu valor está muito próximo do limiar, ou seja, a $10 \%$ ele já é significativo. De fato, é no mínimo prudente prestar atenção nas progênies com excesso de mortalidade, mormente aquela (Progênie 32, Tabela 5) com 19 plantas mortas.

A distribuição de falhas por procedência aos quatro meses de idade também é eqüitativa (Tabela 3). Observa-se que a diferença entre o número observado e o esperado, sob a hipótese de distribuição eqüitativa, não é significativo para nenhuma delas. Aos 12 meses de idade isto não acontece. Os maiores desvios em relação à taxa de mortalidade esperada ocorreram para as procedências de Colombo, PR, e Barão de Cotegipe, RS, estas duas sendo as mais prováveis responsáveis pela significância da estimativa do $\chi^{2}$ (Tabela 3). Observa-se também, nesta mesma tabela, que Barão de Cotegipe, RS, apresentou a menor taxa de mortalidade em ambas as idades, e a maior, aos 12 meses, pertence à procedência de Colombo, PR.

Floss (06), ao comparar a taxa de mortalidade de 15 diferentes procedências em Chapecó, SC, e Três Barras, SC, encontrou, também para a procedência de Barão de Cotegipe, RS, uma das menores taxas de mortalidade avaliadas aos $21,45 \mathrm{e}$ 71 meses de idade.

TABELA 1 - Distribuição de falhas de plantas de erva-mate, por progênie, com quatro meses da data do plantio. Pinhais, PR, 1997

\begin{tabular}{cccc}
\hline $\begin{array}{c}\text { Número de falhas } \\
\text { nas progênies }\end{array}$ & $\mathrm{f}(\mathrm{o})^{1}$ & $\begin{array}{c}\mathrm{f}(\mathrm{e})^{2} \text { Poisson } \\
\text { (média por progênie = 1,59375) }\end{array}$ & $\chi^{2}$ \\
\hline 0 & 13 & 13,002 & 0,00 \\
2 & 21 & 20,723 & 0,00 \\
2 & 15 & 16,513 & 0,14 \\
3 & 10 & 8,772 & 0,17 \\
4 & 4 & 3,495 & - \\
5 & 1 & 1,114 & - \\
Mais que 5 & 0 & 0,381 & $0,31^{\mathrm{ns}}$ \\
Total & 64 & 64 &
\end{tabular}

$1 \quad f(o)=$ Freqüência observada. $\quad 2 \quad f(e)=$ Freqüência estimada. $\quad \chi^{2}=$ Qui-quadrado. $\quad$ ns $=$ não significativo. 
TABELA 2 - Distribuição de falhas de plantas de erva-mate, por progênie, com um ano da data do plantio. Pinhais, PR, 1997

\begin{tabular}{cccc}
\hline $\begin{array}{c}\text { Número de falhas } \\
\text { nas progênies }\end{array}$ & $\mathrm{f}(\mathrm{o})^{1}$ & $\begin{array}{c}\mathrm{f}(\mathrm{e})^{2} \text { Poisson } \\
\text { (média por progênie }=5,15625)\end{array}$ & $\chi^{2}$ \\
\hline 0 & 4 & 0,368849375 & - \\
1 & 3 & 1,901879589 & - \\
2 & 8 & 4,903283315 & - \\
3 & 8 & 8,427518198 & 3,508460 \\
4 & 6 & 10,86359768 & 2,177417 \\
5 & 10 & 11,2030851 & 0,129197 \\
6 & 9 & 9,627651261 & 0,040918 \\
7 & 4 & 7,091796688 & 1,347924 \\
8 & 2 & 4,570884584 & - \\
9 & 2 & 2,61873596 & - \\
10 & 3 & 1,350285729 & - \\
11 & 2 & 0,632946436 & - \\
12 & 0 & 0,271969172 & - \\
13 & 2 & 0,107872388 & - \\
14 & 0 & 0,039729786 & - \\
Mais que 14 & 1 & 0,013657114 & $7,800503^{\mathrm{ns}}$ \\
Total & 64 & 63,99374237 & \\
\hline
\end{tabular}

$1 \quad f(o)=$ Freqüência observada. $\quad 2 \quad f(e)=$ Freqüência estimada. $\quad \chi^{2}=$ Qui-quadrado. $\quad$ ns $=$ não significativo.

TABELA 3 - Distribuição de falhas de erva-mate, por procedência, aos 4 e 12 meses da data de plantio. Pinhais, PR, 1997

\begin{tabular}{|c|c|c|c|c|c|c|}
\hline \multirow{3}{*}{ Procedência } & \multicolumn{6}{|c|}{ Tempo do plantio até a avaliação } \\
\hline & \multicolumn{3}{|c|}{4 meses } & \multicolumn{3}{|c|}{12 meses } \\
\hline & $f(0)$ & $f(e)$ & $\chi^{2}$ & $f(0)$ & $f(e)$ & $\chi^{2}$ \\
\hline Ivaí(PR) & 23 & 20,4 & 0,33 & 54 & 66 & 2,18 \\
\hline Colombo(PR) & 17 & 20,4 & 0,57 & 118 & 66 & 40,96 \\
\hline Barão de Cotegipe(RS) & 16 & 20,4 & 0,94 & 39 & 66 & 11,05 \\
\hline Quedas do Iguaçu(PR) & 20 & 20,4 & 0,01 & 51 & 66 & 3,40 \\
\hline Cascavel(PR) & 26 & 20,4 & 1,54 & 68 & 66 & 0,06 \\
\hline Total & 102 & & $3,39^{\text {ns }}$ & 330 & & 57,65 ** \\
\hline
\end{tabular}

$1 \mathrm{f}(\mathrm{o})=$ Freqüência observada. ${ }^{2} \mathrm{f}(\mathrm{e})=$ Freqüência estimada. $\chi^{2}=$ Qui-quadrado. ${ }^{\mathrm{ns}}=$ não significativo. ${ }^{* *}=$ significativo a $1 \%$.

\section{Análise de variância e comparação de médias para o caráter altura de planta}

O modelo $\left(Y_{i j k}=m+p f_{i}+r_{i}+e_{i j}+d_{i j k}\right)$, originalmente proposto, foi concebido na hipótese de ausência de efeito de procedências. Para se testar o efeito de procedências (Tabela 4), o efeito $p f_{i}$ (procedências + famílias) foi decomposto em procedências e famílias (progênies) dentro de procedências.

Com exceção do efeito progênie/Cascavel e do erro, todos os efeitos do modelo foram significativos (Tabela 4). Por esta mesma tabela, observa-se que o efeito de procedências foi altamente significativo.

A decomposição ortogonal dos 59 graus de liberdade do efeito progênies/procedências, que é significativo, mostra que o efeito progênies/Barão de Cotegipe, RS, é o mais significativo (Tabela 4).
Conforme ressalta Resende et al. (09), considerando-se que o objetivo do melhorista é promover o aumento contínuo da expressão dos vários caracteres de interesse, deve-se partir de uma população original (germoplasma base) que tenha variabilidade genética e média altas. Os resultados das Tabelas 4 e 6 mostram que a procedência de Barão de Cotegipe, RS, é a que atende melhor estes requisitos para o caráter em questão.

Os resultados da Tabela 6 são, também, indicativos da importância de se testar diferentes procedências, em um programa de melhoramento, principalmente em sua fase inicial. Tal assertiva é válida mesmo considerando-se, conforme literatura (02, 05 e 07), que a maior parte da variabilidade genética está dentro e não entre as populações, em espécies florestais tropicais e temperadas. 
FERNANDES, J. S. C. et al. Estimativas de Parâmetros...

TABELA 4 - Análise de variância para o caráter altura de planta $(\mathrm{cm})$ na cultura da erva-mate com um ano da data de plantio. Pinhais, PR, 1997

\begin{tabular}{|c|c|c|c|c|c|}
\hline Fonte da Variação & $\begin{array}{l}\text { Graus de } \\
\text { Liberdade }\end{array}$ & $\begin{array}{c}\text { Soma de } \\
\text { Quadrados }\end{array}$ & $\begin{array}{c}\text { Quadrados } \\
\text { Médios }\end{array}$ & $\mathrm{F}$ & $E(Q M)$ \\
\hline BLOCOS & 8 & 10312,7 & 1289,0908 & $32,0822^{* *}$ & $v_{d} / n+v_{e}+g v_{b}$ \\
\hline Progênie + Procedência & 63 & 15445,7 & 245,1701 & $6,1017^{\star *}$ & $v_{d} / n+v_{e}+r v_{(f+p)}$ \\
\hline Procedência & 4 & 7191,3 & 1797,8128 & $44,7430^{* *}$ & $v_{d} / n+v_{e}+r g v_{p}$ \\
\hline Progênie/Procedência & 59 & 8254,5 & 139,9062 & $3,4819^{* *}$ & $v_{\mathrm{d}} / n+v_{\mathrm{e}}+r v_{\mathrm{f} / \mathrm{p}}$ \\
\hline Progênie/Ivaí(PR) & 12 & 1030,7 & 85,8877 & $2,1375_{* *}^{*}$ & $v_{d} / n+v_{e}+r v_{f / p 1}$ \\
\hline Progênie/Colombo(PR) & 12 & 2228,5 & 185,7093 & $4,6218^{* *}$ & $v_{d} / n+v_{e}+r v_{f / p 2}$ \\
\hline Progênie/Barão de Cotegipe(RS & 11 & 2613,8 & 237,6177 & $5,9137^{* *}$ & $v_{d} / n+v_{e}+r v_{f / p} 3$ \\
\hline Progênie/Quedas do lguaçu & 12 & 1798,7 & 149,8931 & $3,7305^{\star *}$ & $v_{d} / n+v_{e}+r v_{f / p} 4$ \\
\hline Progênie/Cascavel & 12 & 582,8 & 48,5658 & $1,2087^{\mathrm{ns}}$ & $v_{d} / n+v_{e}+r v_{f / p 5}$ \\
\hline ERRO & 504 & 20251,2 & 40,1809 & $1,6116^{\mathrm{ns}}$ & $v_{d} / n+v_{e}$ \\
\hline DENTRO & 2550 & 63577,6 & 24,9324 & & $\mathrm{v}_{\mathrm{d}} / \mathrm{h}$ \\
\hline \multirow[t]{2}{*}{ TOTAL } & 3125 & 591531,4 & & & \\
\hline & & Estimativas & & & \\
\hline$V_{d}=$ & 135,3829 & $V_{b}=$ & 19,5142 & $\mathrm{CV}_{\mathrm{e}}=$ & $18,7 \%$ \\
\hline$V_{e}=$ & 15,2485 & $V_{f} / p=$ & 11,0806 & $\mathrm{CV}_{\mathrm{g}}=$ & $19,7 \%$ \\
\hline$\sigma_{\mathrm{A}}^{2}=$ & 44,3224 & $\mathrm{~h}_{\mathrm{i}}^{2}=$ & $24,5 \%$ & $M G=$ & 33,8253 \\
\hline
\end{tabular}

Legenda: $v_{d}=$ variância dentro; $v_{e}=$ variância do erro; $v_{p}=$ variância entre procedências; $v_{(f+p)}=$ variância entre famílias, incluindo-se efeitos de procedências; $v_{f / p}=$ variância entre famílias dentro de procedências; $v_{f / p 1} a v_{f / p 5}=$ variância entre progênies dentro das respectivas procedências; $v_{b}=$ variância entre blocos; $n=$ número médio de plantas por parcela; $r$ =número de repetições; $g=$ número de progênies; $\mathrm{CV}_{\mathrm{e}}=$ coeficiente de variação experimental; $\mathrm{CV}_{\mathrm{g}}=$ coeficiente de variação genético; ${ }^{*} \mathrm{e}{ }^{* *}$ significativos a $5 \%, 1 \%$, respectivamente; e ns = não significativo.

Observa-se também (Tabela 4) que o efeito de blocos foi altamente significativo. Como estes foram dispostos aproximadamente em nível, num terreno ligeiramente inclinado ( $\pm 20 \%$ de inclinação), conclui-se que a causa mais provável para tal significância é a umidade. A hipótese de que esta significância possa ser explicada pelas propriedades químicas do solo pode ser descartada, uma vez que praticamente não houve diferenças significativas entre os blocos para as variáveis indicadoras de fertilidade do solo (dados não publicados).

Observando-se as comparações de médias pelo teste Tukey (Tabela 5), verifica-se que pelo menos sete progênies, todas de Barão de Cotegipe, RS, pertencem ao grupo das superiores para o caráter em questão. Por outro lado, pelo menos 11 progênies de Colombo, PR, estão entre as inferiores (Tabela 5). Tais resultados são corroborados também pela Tabela 6. Nesta tabela, verifica-se que Barão de Cotegipe, RS, está em primeiro lugar e Colombo, PR, em último.

O significado destes resultados deverá ser melhor explorado considerando-se que o município de Colombo, PR, é praticamente contíguo ao local deste experimento, enquanto que Barão de Cotegipe, RS, é o que se encontra mais afastado. Observação semelhante foi apontada (06) em um ensaio conduzido em Chapecó, SC, e Três Barras, SC, onde foram testadas 15 procedências de ervamate. $\mathrm{O}$ autor verificou, para todas as características avaliadas (diâmetro da copa, altura e densidade foliar), a ausência de populações próximas dos locais de avaliação no grupo das melhores. Estes autores citam ainda que Shimizu e Higa (1980) e Gianotti et al. (1982) observaram comportamento semelhante em Araucaria angustifolia.

\section{Estimativas de parâmetros genéticos}

$\mathrm{Na}$ Tabela 4 encontram-se algumas estimativas de importância para o melhoramento do caráter altura de plantas, caso ele venha a ser correlacionado com a produção de massa verde em idades posteriores da planta.

É possível, a partir destas estimativas, estimar-se outras herdabilidades para os efeitos definidos no modelo, além da herdabilidade da população mostrada na Tabela 4.

Usando-se os estimadores definidos na metodologia e as estimativas para os parâmetros que compõem as mesmas, tem-se:

$$
\begin{aligned}
& h_{d}^{2}=\frac{\left(1-\frac{1}{4}\right) 44,32}{135,38}=24,6 \% \\
& h_{p}^{2}=\frac{\frac{(1-1 / 4)}{5,43} 44,32}{44,32+\frac{135,38}{5,43}}=8,8 \% ;
\end{aligned}
$$




$$
\begin{aligned}
& h_{f}^{2}=\frac{\frac{\left(1+(9 \times 5,43-1) \frac{1 / 4}{4}\right)}{9 \times 5,43} 44,32}{11,08+\frac{15,25}{9}+\frac{135,38}{9 \times 5,43}}=75,6 \% ; \mathrm{e} \\
& h_{r}^{2}=\frac{\frac{(1-1 / 4)}{64 \times 5,43} 44,32}{11,08+\frac{15,25}{9}+\frac{135,38}{64 \times 5,43}}=0,7 \%,
\end{aligned}
$$

É importante discutir aqui as herdabilidades associadas ao efeito de parcelas e blocos. Dependendo do número de indivíduos por parcela e do número de famílias testadas, a contribuição destas herdabilidades poderá variar. Resende e Higa (08) mostraram um aumento na eficiência seletiva variando de $4,2 \%$ a $7 \%$ em relação ao procedimento sem a inclusão destes efeitos. Entretanto, este aumento é em grande parte devido à contribuição do efeito de parcelas. Os dados acima estão de acordo com estas informações quando se compara a herdabilidade associada ao efeito de parcelas $(8,8 \%)$ com aquela associada ao efeito de blocos (0,7\%). Esta última é, de fato, muito pequena. É oportuno lembrar também que $(24,6 \%)$ e $(24,5 \%$, Tabela 6), embora numericamente semelhantes, não são a mesma coisa. As duas referem-se à herdabilidade no sentido restrito e em nível de indivíduo, mas a primeira é dentro de parcelas e a segunda é no experimento.

Estimativas de herdabilidades, no sentido restrito e em nível de indivíduos, para caracteres de crescimento em erva-mate são mencionadas (09). Para o caráter altura de planta, estes autores mencionam uma estimativa de $5,0 \%$. Tal estimativa é muito inferior àquela $(24,5 \%)$ encontrada no presente trabalho (Tabela 4). É possível, e até provável, que esta diferença não tenha como causa apenas o fato de se tratar de diferentes populações e ambientes. Deve-se considerar também o fato de que as citações destes autores referem-se a plantas em idade adulta e, no presente trabalho, a plantas com um ano. Plantas adultas já foram podadas várias vezes e, provavelmente, expressarão seu vigor mais em número de galhos do que em altura. Tal hipótese pode ser fundamentada considerandose que Sturion et al. (09) mencionam uma estimativa, para a herdabilidade em questão, de 19,0\% para o caráter produção de massa verde, na mesma população e ambiente.

Outro aspecto importante a ser comentado é a relação entre o coeficiente de variação genético (neste caso aditivo) e o coeficiente de variação experimental. No presente trabalho, este quociente é de 1,05 (Tabela 4). Esta é uma condição muito favorável ao melhoramento (13). Especificamente para o caráter em questão, na hipótese de se verificar correlações significativas deste com produção de massa verde na fase adulta da planta, este resultado também é animador.

TABELA 5 - Média, por progênie, de altura $(\mathrm{cm})$ de plantas de erva-mate com um ano da data do plantio.

\begin{tabular}{|c|c|c|c|c|c|c|c|}
\hline \multirow[b]{2}{*}{ Progênie } & \multirow[b]{2}{*}{ Procedência } & \multirow[b]{2}{*}{$\mathrm{NPP}_{1}$} & \multirow[b]{2}{*}{$\mathrm{MP}^{2}$} & \multicolumn{3}{|c|}{ Em ordem decrescente de altura } & \multirow{2}{*}{$\begin{array}{c}\text { Tukey } \\
\text { DMS }^{3}=12,3\end{array}$} \\
\hline & & & & Progênie & Procedência & $\mathrm{MP}^{2}$ & \\
\hline 6 & Ivaí(PR) & 50 & 30,4 & 68 & Barão de Cotegipe (RS) & 48,3 & A \\
\hline 7 & Ivaí(PR) & 52 & 29,6 & 70 & Barão de Cotegipe (RS) & 44,1 & A \\
\hline 8 & Ivaí(PR) & 44 & 26,9 & 57 & Barão de Cotegipe (RS) & 41,5 & A \\
\hline 9 & Ivaí(PR) & 51 & 30,3 & 87 & Quedas do lquacu (PR) & 40,2 & A \\
\hline 11 & lvaí(PR) & 54 & 33,4 & 67 & Barão de Coteaipe (RS) & 39.8 & A \\
\hline 13 & Ivaí(PR) & 52 & 32,8 & 157 & Cascavel (PR) & 39,8 & A \\
\hline 14 & Ivaí(PR) & 48 & 35,3 & 96 & Quedas do lguaçu (PR) & 39,7 & A \\
\hline 15 & Ivaí(PR) & 51 & 33,3 & 158 & Cascavel (PR) & 39,7 & A \\
\hline 16 & Ivaí(PR) & 50 & 35,1 & 97 & Quedas do lquacu (PR) & 39,3 & A \\
\hline 19 & Ivaí(PR) & 49 & 29,6 & 95 & Quedas do lquacu (PR) & 38,8 & A \\
\hline 20 & Ivaí(PR) & 46 & 29,4 & 34 & Colombo (PR) & 38,6 & A \\
\hline 21 & Ivaí(PR) & 52 & 37,2 & 100 & Quedas do Iguaçu (PR) & 38,3 & A \\
\hline 22 & Ivaí(PR) & 49 & 35,9 & 58 & Barão de Coteqipe (RS) & 37,7 & A \\
\hline 31 & Colombo (PR) & 47 & 25,9 & 166 & Cascavel (PR) & 37,7 & A \\
\hline 32 & Colombo (PR) & 35 & 25,9 & 98 & Quedas do Iguaçu (PR) & 37,7 & A \\
\hline 33 & Colombo (PR) & 47 & 26,9 & 21 & Ivaí (PR) & 37,2 & A \\
\hline 34 & Colombo (PR) & 54 & 38.6 & 64 & Barão de Coteqipe (RS) & 36.9 & A \\
\hline 37 & Colombo (PR) & 43 & 27,1 & 155 & Cascavel (PR) & 36,9 & A \\
\hline 38 & Colombo (PR) & 48 & 24,3 & 163 & Cascavel (PR) & 36,8 & A \\
\hline 40 & Colombo (PR) & 41 & 24,8 & 83 & Quedas do Iguaçu & 36,4 & A \\
\hline 41 & Colombo (PR) & 43 & 26,0 & 154 & Cascavel (PR) & 36,4 & A \\
\hline 42 & Colombo (PR) & 51 & 33,0 & 66 & Barão de Cotegipe (RS) & 36,2 & A \\
\hline 43 & Colombo (PR) & 41 & 19,9 & 22 & Ivaí (PR) & 35,9 & \\
\hline 45 & Colombo (PR) & 44 & 29,2 & 14 & Ivaí (PR) & 35,3 & \\
\hline 47 & Colombo (PR) & 45 & 25,7 & 153 & Cascavel (PR) & 35,3 & \\
\hline 49 & Colombo (PR) & 45 & 28,9 & 71 & Barão de Cotegipe (RS) & 35,1 & \\
\hline
\end{tabular}

Pinhais, PR, 1997

continua 
continuação

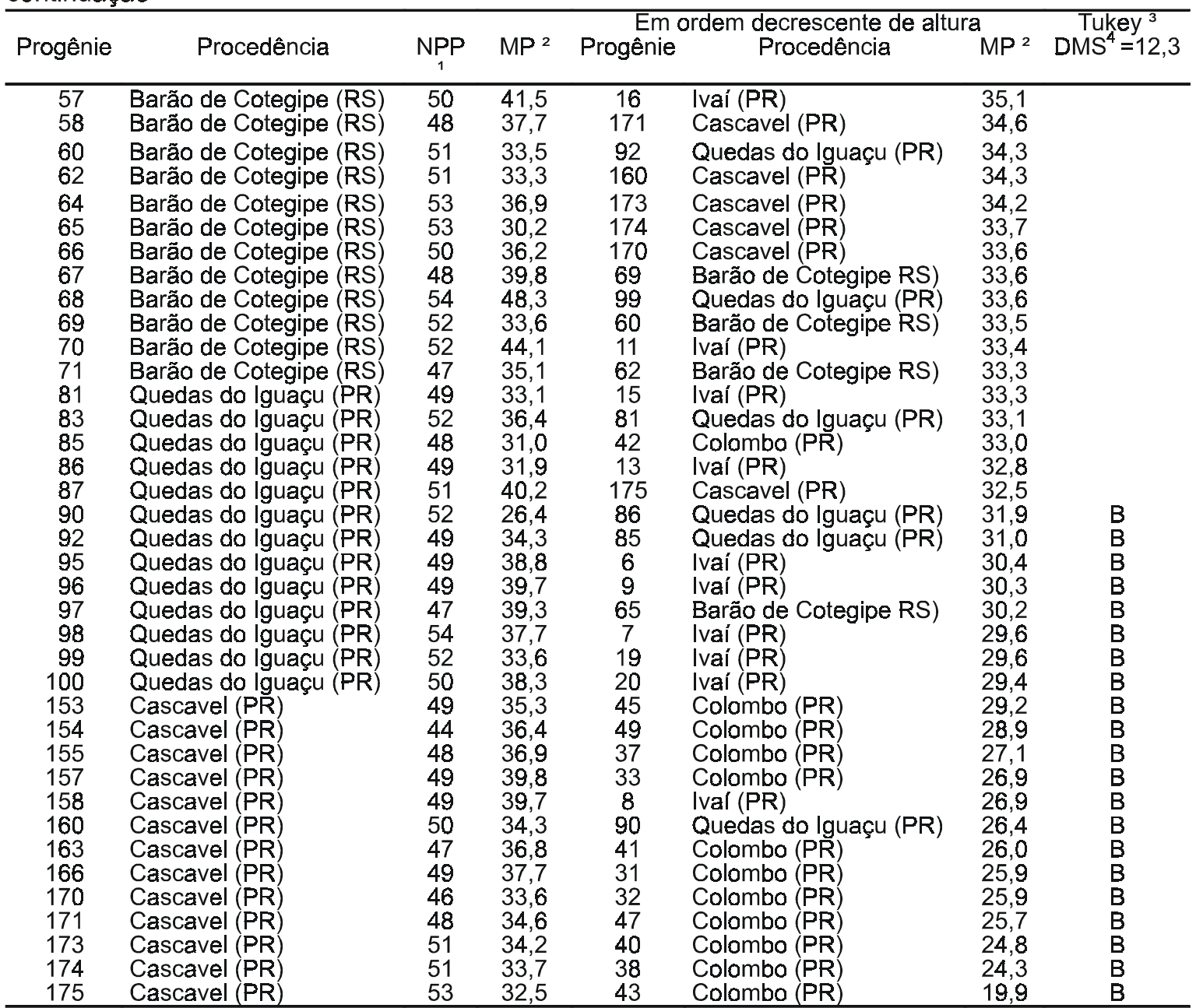

${ }^{1} \mathrm{NPP}=$ Número de plantas por progênie. $\quad{ }^{2} \mathrm{MP}=$ Média da Progênie.

${ }^{3}$ Médias seguidas da mesma letra não diferem significativamente pelo teste de Tukey a $5 \%$ de probabilidade.

${ }^{4}$ DMS = Diferença Mínima Significativa.

${ }^{5}$ Devido às sobreposições, foram delimitados apenas dois grupos no teste de Tukey.

TABELA 6 - Média, por procedência, de altura $(\mathrm{cm})$ de plantas de erva-mate com um ano da data do plantio. Pinhais, PR, 1997

\begin{tabular}{lcc}
\hline \multicolumn{1}{c}{ Procedência } & Média & $\begin{array}{c}\text { Tukey }{ }^{1} \\
\text { DMS }^{2}=2,3\end{array}$ \\
\hline Barão de Cotegipe (RS) & 37,5 & $\mathrm{~A}$ \\
Cascavel (PR) & 36,0 & $\mathrm{~A}$ \\
Quedas do Iguaçu (PR) & 35,4 & $\mathrm{~A}$ \\
Ivaí (PR) & 32,2 & $\mathrm{~B}$ \\
Colombo (PR) & 27,4 & $\mathrm{C}$ \\
\hline
\end{tabular}

1 Médias seguidas da mesma letra não diferem significativamente pelo teste de Tukey a 5\% de probabilidade.

$2 \quad$ DMS = Diferença Mínima Significativa. 


\section{CONCLUSÕES}

1) A distribuição de mortalidade aos quatro meses da data de plantio não foi influenciada por progênies ou procedências. Aos 12 meses, entretanto, houve evidências de maior suscetibilidade à mortalidade de certas progênies e, principalmente, procedências.

2) A análise de variância mostrou, para o caráter altura de planta com um ano da data de plantio, efeitos significativos para procedências e progênies.
3) A estimativa da herdabilidade no sentido restrito e em nível de indivíduo, para o caráter altura de planta com um ano da data de plantio, foi de $24,5 \%$. Esta herdabilidade torna promissora a seleção em estádio precoce, caso seja confirmada a correlação genética deste caráter com a produção de biomassa na fase adulta da planta.

4) As progênies de Barão de Cotegipe, RS, apresentaram maior média e maior variância genética aditiva para o caráter altura de planta, e menor taxa de mortalidade.

\section{REFERÊNCIAS}

01 BELINGHERI, L.D.; PRAT-KRICUN, S.D. Selección de plantas. In: CURSO DE CAPACITACION EN PRODUCION DE YERBA MATE (1.: Cerro Azul: 1992). Resúmenes. Cerro Azul: INTA, Estacion Experimental Agropecuária de Cerro Azul, 1992. p.17-21.

02 BOYLE, T.J.B.; YEH, F.C. Within-population genetic variation - Implications for selection and breeding. In: SYMMPOSIUM ON TREE IMPROVEMENT (21.:Truro: 1987). Proceedings. Ottawa: Canadian Forestry Service, 1987. p.20-40.

03 CARPANEZZI, A.A.; ZANON, A.; IEDE, E.T.; STURION, J.A.; GRAÇA, M.E.C.; LOURENÇO, R.A. Diretrizes de pesquisa aplicada para plantios de erva-mate no Brasil. In: CONGRESSO FLORESTAL DO PARANÁ (2.: Curitiba: 1988). Resumos. Curitiba: Instituto Florestal do Paraná, 1988. p.59.

04 COELHO, J.G.L. Prefácio. In: ERVA-MATE: BIOLOGIA E CULTURA NO CONE SUL (1.: Porto Alegre, 1992). Anais. Porto Alegre: Editora da Universidade/UFRGS, 1995. p.9-10.

05 DIAS, L.A.S.; KAGEYAMA, P.Y. Variação genética em espécies arbóreas e consequências para o melhoramento florestal. Agrotrópica. 3:119-127, 1991.

06 FLOSS, P.A. Variações genéticas entre populações naturais de Ilex paraguariensis St. Hil. (erva-mate) avaliadas em Chapecó, SC e Três Barras, SC. Piracicaba: 1994. 94p. Tese (Mestrado em Ciências Florestais) - Curso de PósGraduação em Ciências Florestais, Escola Superior de Agricultura "Luiz de Queiroz"/Universidade de São Paulo.

07 HAMRICK, J.L.; LOVELESS, M.D. Isozyme variation in tropical trees: procedures and preliminary results. Biotrópica, New Orleans, 18:201-207, 1986.

08 RESENDE, M.D.V.; HIGA, A.R. Maximização da eficiência da seleção em testes de progênies de Eucalyptus através da utilização de todos os efeitos do modelo matemático. Boletim de Pesquisa Florestal, Colombo, 29:37-55, 1994b.

09 RESENDE, M.D.V.; STURION, J.A.; MENDES, S. Genética e melhoramento da erva-mate (Ilex paraguariensis St. Hil.). Colombo: EMBRAPA-CNPF, 1995. 33p. (Documento n. 25).

10 RESENDE, M.D.V.; VENCOVSKY, R. (1990). Condução e utilização de bancos de conservação genética de espécies de eucalipto. In: CONGRESSO FLORESTAL BRASILEIRO (6.: Campos do Jordão, 1990). Anais. São Paulo: Sociedade Brasileira de Silvicultura, 1990. p.434-439.

11 RODIGHERI, H.R.; NETO, L.S.; CICHACZEWSKI, I.F. Custos, produtividade e renda da erva-mate cultivada na região de Guarapuava, PR. Colombo: EMBRAPA/CNPF, 1995. 22p. (Documento n. 24).

12 STURION, J.A. \& RESENDE, M.D.V. Programa de melhoramento genético da erva-mate no Centro Nacional de Pesquisas de Florestas da EMBRAPA. In: CONGRESSO SUL AMERICANO DE ERVA-MATE, 1. REUNIÃO TÉCNICA DO CONESUL SOBRE A CULTURA DA ERVA-MATE, 2 (1.2.: Curitiba, 1997). Anais. Colombo: EMBRAPA/CNPF, 1997. p285-297.

13 VENCOVSKY, R.; BARRIGA, P. Genética biométrica no fitomelhoramento. Ribeirão Preto: Sociedade Brasileira de Genética, 1992. 486p.

14 WINGE, H.; FERREIRA, A.G.; MARIATH, J.E.A.; TARASCONI, L.C. Apresentação. In: ERVA-MATE: BIOLOGIA E CULTURA NO CONE SUL (1.: Porto Alegre, 1992). Anais. Porto Alegre: Editora da Universidade/UFRGS, 1995. p.11-13. 